\title{
Initiation and progression of ossification of the posterior longitudinal ligament of the cervical spine in the hereditary spinal hyperostotic mouse (twy/twy)
}

\author{
Kenzo Uchida $\cdot$ Takafumi Yayama $\cdot$ Daisuke Sugita $\cdot$ Hideaki Nakajima $\cdot$ \\ Alexander Rodriguez Guerrero • Shuji Watanabe • Sally Roberts • \\ William E. Johnson • Hisatoshi Baba
}

Received: 4 January 2011/Revised: 31 May 2011/Accepted: 31 July 2011/Published online: 18 August 2011 (C) The Author(s) 2011. This article is published with open access at Springerlink.com

\begin{abstract}
Introduction Ossification of the posterior longitudinal ligament (OPLL) is a significantly critical pathology that can eventually cause serious myelopathy. Ossification commences in the vertebral posterior longitudinal ligaments, and intensifies and spreads with the progression of the disease, resulting in osseous projections and compression of the spinal cord. However, the paucity of histological studies the underlying mechanisms of calcification and ossification processes remain obscure. The pathological process could be simulated in the ossifying process of the ligament in mutant spinal hyperostotic mouse (twy/twy). The aim of this study is to observe that enlargement of the nucleus pulposus followed by herniation, disruption and regenerative proliferation of annulus fibrosus cartilaginous tissues participated in the initiation of ossification of the posterior longitudinal ligament of twy/twy mice.
\end{abstract}

Electronic supplementary material The online version of this article (doi:10.1007/s00586-011-1971-7) contains supplementary material, which is available to authorized users.

K. Uchida $(\bowtie) \cdot$ T. Yayama $\cdot$ D. Sugita $\cdot$ H. Nakajima

A. Rodriguez Guerrero $\cdot$ S. Watanabe $\cdot$ H. Baba

Department of Orthopaedics and Rehabilitation Medicine,

Faculty of Medical Sciences, University of Fukui,

Matsuoka Shimoaizuki 23-3, Eiheiji, Fukui 910-1193, Japan

e-mail: kuchida@u-fukui.ac.jp

S. Roberts

Institute for Science and Technology in Medicine,

Keele University at the RJAH Orthopaedic Hospital, Oswestry,

Shropshire SY10 7AG, UK

W. E. Johnson

Life and Health Sciences, Aston University, Aston Triangle, Birmingham B4 7ET, UK
Materials and methods The mutant twy/twy mice (6 to 22-week-old) were used in the present study. The vertebral column was analyzed histologically and immunohistochemically.

Results We observed that the enlargement of the nucleus pulposus followed by herniation, disruption and regenerative proliferation of annulus fibrosus cartilaginous tissues participated in the initiation of ossification of posterior longitudinal ligament of $t w y / t w y$ mice. In this regards, the cells of the protruded hyperplastic annulus fibrosus invaded the longitudinal ligaments and induced neovascularization and metaplasia of primitive mesenchymal cells to osteoblasts in the spinal ligaments of $t w y / t w y$ mice.

Conclusion Since genetic mechanisms could play a role in human OPLL, the age-related enlargement of the nucleus pulposus in the twy/twy mouse may primarily occur as a result of overproduction of mucopolysaccharide matrix material induced by certain genetic abnormalities.

Keywords Ossification of the posterior longitudinal ligament (OPLL) · Twy/twy mouse · Nucleus pulposus herniation $\cdot$ Annulus fibrosus $\cdot$ Enchondral ossification

\section{Introduction}

Ossification of the posterior longitudinal ligament (OPLL) is a pathological condition that can cause serious myeloradiculopathy $[2,29]$. Ossification commences in the vertebral posterior longitudinal ligaments, with a particular predilection for the cervical area, but intensifies and spreads with the progression of the disease, resulting in osseous projections and compression of the spinal cord [3, 24]. OPLL was previously considered to be specific to Asian people [15] and did not attract attention in Europe or 
the United States. However, because of the reports that about half of the patients with diffuse idiopathic skeletal hyperostosis (DISH) (Forestier disease), which is well known in Europe and the United States, had OPLL, this disease has been recognized as a subtype of DISH [21, 22]. A number of epidemiological [18, 20], metabolic [25, 26], mechanical [4, 16, 28], and biological factors are suspected to contribute to the development as well as progression of OPLL. In addition, gene analysis [6, 14, 23] has been applied to clarify the underlying genetic background because of the high prevalence of OPLL in certain countries and/or races. Thus, recent research on OPLL involves association and/or genome-wide linkage analyses $[6,8,23]$ to determine the candidate genes, and proteomics analysis for detecting causative peptides in the ossifying plaque.

Histochemical studies of OPLL have demonstrated certain characteristics including the presence of several different phenotypic osteoblasts in ligament cells obtained from non-ossified sites, high alkaline phosphatase (ALP) activity, parathyroid hormone- and prostaglandin E2-stimulated increases in cAMP, and responses to both calcification and 1,25-dihydroxycholecalcifenol (1,25(OH)2D3) [10]. In addition to these systemic predispositions, multiple local factors have been proposed for the pathogenesis of OPLL. Using immunohistochemical techniques, Kawaguchi et al. [11] demonstrated the presence of bone morphogenetic protein-2 (BMP-2) inducing cartilage and bone formation, and transforming growth factor-beta (TGF- $\beta$ ) stimulating bone formation in the ossified ligaments of OPLL. While these findings are interesting, the tissues examined in their report were mostly surgically resected materials or autopsy specimens from patients with a late stage disease. Furthermore, abnormal enchondral ossification $[1,5]$ may play a role in OPLL, but because of the paucity of histological studies the underlying mechanisms of calcification and ossification processes remain obscure.

To clarify the pathogenesis of OPLL and to develop new treatments to combat the ossification of the ligaments, reliable animal models are necessary. The tiptoe walking Yoshimura mouse (twy) was first introduced by Hosoda et al. [9]. The mode of inheritance is autosomal recessive with complete penetrance. Progression of ectopic ossification in the mice is monitored by the contracture of the limb joints, which leads to characteristic "tiptoe" walking. The mouse exhibits ossification of various soft tissues such as tendons, cartilage, and ligaments in the extremities and the spine, in particular the ossification of the spinal ligaments is similar to that seen in human OPLL $[7,19]$. The ossification occurs immediately after weaning and progresses within a short period of time.

The present study was designed to investigate serial histological changes in the longitudinal ligaments leading to the ossification in the twy/twy mouse spinal ligaments. We also studied immunohistological changes in the area around the intervertebral discs, vertebral endplate and the posterior longitudinal ligaments of $t w y / t w y$ mice.

\section{Materials and methods}

\section{Experimental animals}

Thirty-one twy/twy mice (Central Institute for Experimental Animals, Kawasaki, Japan), 6- to 22-week-old, weighing $25-31 \mathrm{~g}$ (mean \pm standard deviation, $28 \pm 3 \mathrm{~g}$ ) were used in the present study. Mice were confirmed to have OPLL in the cervical spine by contact microradiography (Softex-CMR; Softex, Osaka, Japan), at the time of commencement of the study when they were 6 weeks old and at 10, 18 and 22 weeks of age when killed. The mutant twy/ twy mice were maintained by brother-sister mating of heterozygous mice $(+/ t w y)$ and the animal exhibits paravertebral ossification and demonstrates prominent cervical OPLL at 10-14 weeks of age, eventually presenting with extensive spinal ankylosis, involving both the anterior and posterior vertebral columns [7, 9, 19]. Institute of Cancer Research (ICR) mice, age-matched with the $t w y / t w y$ mice, were used as controls $(n=15)$. The Ethics Review Committee for Animal Experimentation of our University approved the experimental protocol.

\section{Casting of microvascular mesh with carbon black} gelatin

After anesthesia with an intraperitoneal injection, the animals were exsanguinated through cardiac puncture, perfusion of Ringer lactate (Lactec, Ohtsuka, Tokyo) together with carbon-black gelatin solution consisting of India ink (Kuretake, Nara, Japan) The vertebral column was dissected en bloc and then bisected sagittally in the median plane followed by fixation with $10 \%$ buffered formaldehyde at $4^{\circ} \mathrm{C}$ for $48 \mathrm{~h}$. The specimen was further decalcified for 7-14 days at $4^{\circ} \mathrm{C}$ in $0.5 \mathrm{M}$ EDTA, and embedded with paraffin. Serial $4 \mu \mathrm{m}$ thick sections were stained with hematoxylin-eosin (HE).

Immunohistochemical staining

Serial $4 \mu \mathrm{m}$-thick sections were prepared from the paraffinembedded specimens, deparaffinized with xylene and replaced with ethanol. After washing with water, the intrinsic peroxidase was blocked with $0.3 \% \mathrm{H}_{2} \mathrm{O}_{2}$ solution. The sections were irradiated three times, using a microwave oven (500 W, ER-245, Toshiba, Tokyo). Then they were reacted with BLOCKING (LSAB kit, Lot. No. 00075, 
DAKO, Glostrup, Denmark) at $20^{\circ} \mathrm{C}$ for $10 \mathrm{~min}$. This was followed by reaction with the following primary antibodies, respectively, at $4^{\circ} \mathrm{C}$ overnight: monoclonal anti-proliferating cell nuclear antigen (PCNA) antiserum (mouse, PC10, NC-012, Lot. 499, Novocastra Laboratory, Newcastle, United Kingdom); polyclonal anti-S-100 protein (rabbit, Lot. 089Ec, DAKO); monoclonal anti-chondroitin4-sulfate proteoglycan (mouse, Di-4S, Lot. 93901, Seikagaku Kogyo, Tokyo). The sections were further reacted with LINK (biotinylated anti-mouse and anti-rabbit immunoglobulins in PBS, containing carrier protein and $15 \mathrm{mM}$ sodium azide, LSAB kit, DAKO) at $20^{\circ} \mathrm{C}$ for $60 \mathrm{~min}$, and allowed to react with streptavidin solution (streptavidin conjugated to horseradish peroxidase in Tris- $\mathrm{HCl}$ buffer, LSAB kit, DAKO) at $20^{\circ} \mathrm{C}$ for $30 \mathrm{~min}$. To visualize the peroxidase color reaction, the sections were incubated with $\mathrm{DAB}$ solution (DAB, CB090, Dojin Chemicals, Kumamoto, Japan) at $20^{\circ} \mathrm{C}$ for 10 min. Nuclear counterstaining was carried out with hematoxylin). Sections stained for chondroitin 4-sulfate proteoglycan were pretreated with chondroitinase $\mathrm{ABC}$ (Lot. KE94801 Seikagaku Kogyo), and then reacted with avidinFITC (Lot. 090617, E.Y. Laboratory, San Mateo, CA) after reacting with the streptavidin solution. The FITC fluorescence was observed under a confocal laser scanning microscope (CLSM, LSM-GB, Olympus, Tokyo). Argon laser was used as the light source with $488 \mathrm{~nm}$ as the excitation light The FITC image was superimposed on the differential interference image on the background histology.

\section{Alkaline phosphatase staining}

Tissues were prepared for ALP staining according to the method described by Watanabe and Fishman [30]. The entire vertebral column was dissected en bloc and bisected sagittally in the median plane followed by fixation in $10 \%$ buffered formaldehyde for $24 \mathrm{~h}$ at $4^{\circ} \mathrm{C}$, and further decalcified for 4-7 days in $0.5 \mathrm{M}$ EDTA at $4^{\circ} \mathrm{C}$. The $10 \mu \mathrm{m}$ frozen sections were allowed to thaw in a reaction solution containing $10 \mathrm{mg}$ naphthol AS-BI phosphate acid sodium salt (Lot. CAN9061, Wako Chemicals) and $10 \mathrm{mg}$ Fast red violet LB salt (Lot. 07911PT, Andrich, UK) dissolved in $20 \mathrm{ml}$ $0.05 \mathrm{M}$ Tris-HCl buffer. After washing with water, nuclear counterstaining was carried out with hematoxylin, and mounted with glycerin (Lot. SDQ1161, Wako Chemicals).

\section{Results}

$H \& E$ stained sections with casting of microvascular meshes

In 22-week-old twy/twy mouse, there were osseous lesions in the longitudinal ligament between both upper and lower vertebral columns, compared to control mouse (Fig. 1). At the age of 6 weeks, the volume of the nucleus pulposus in the intervertebral discs of all regions of $t w y / t w y$ mice began to increase causing herniation into the anterior and posterior regions, although the nucleus moved mainly in the latter direction. Herniation of the nucleus pulposus subsequently caused irregular rupture of the annulus fibrosus cartilaginous tissue. The ruptured annulus fibrosus cartilaginous cells showed reactive hyperplasia, and the fine meshes of new capillaries were elongated from the enthesis portions toward the tops of the protruded annulus fibrosus cartilaginous tissues (Fig. 2a). Further enlargement of the nucleus pulposus was noted with time; at the age of 18 weeks, twy mice showed a cluster of primitive mesenchymal cells resembling osteoblasts in the vicinity of newly formed vascular meshes in the longitudinal ligaments, both anteriorly and posteriorly and the fronts of the protrusions of reactively hyperplastic annulus fibrosus invaded the longitudinal ligaments, accompanied by a more abundant capillary network (Fig. 2b). At 22 weeks of age, the enlarged nucleus pulposus with herniation, and the rupture of the annulus fibrosus became extremely prominent, with marked increase in the number of osteoblast-like primitive mesenchymal cells. The herniated nucleus pulposus merged with the proper nucleus pulposus located in the center of the intervertebral disc. At this stage, enchondral ossifications began to develop in the cartilaginous cells at the fronts of the protruded and ruptured annulus fibrosus. Furthermore, ossification also occurred near the clusters of osteoblast-like cells at this stage, and both ossifications, enchondral and membranous, fused together forming osseous bridges in the longitudinal ligament between the upper and lower vertebrae (Fig. 2c).

Immunohistochemical staining

PCNA-positive cells began to appear in 6-week-old twy/twy mice, and continued to be observed there among the annulus fibrosus cartilaginous cells surrounding the herniated nucleus pulposus and those at the fronts of protrusions and invasions into the longitudinal ligaments (Fig. 3a). In twy/twy mice older than 18 weeks, when the fronts of ruptured annulus fibrosus invaded the longitudinal ligaments, large numbers of PCNA-positive cartilaginous cells were detected in the longitudinal ligaments (Fig. 3b). The calcium binding protein, S-100, was strongly and specifically positive in the annulus fibrosus cartilaginous cells and in the hypertrophic cartilaginous cells in the endplate at all ages. The cartilaginous cells invading the longitudinal ligaments protruding from the ruptured annulus fibrosus cartilaginous tissue in twy mice were also all positive for S-100 protein and increased with twy/twy mouse aging (Fig. 3c, d). The chondroitin 4-sulfate proteoglycan was 


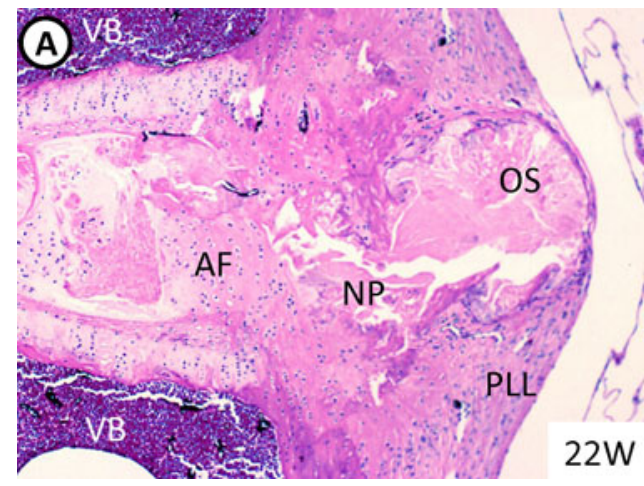

Fig. 1 Photographs showing hematoxylin and eosin (H\&E) staining of 22-week-old twy/twy mouse cervical spine samples (a) and ICR mouse as a control (b). Compared with a control mouse, there are osseous lesions in the longitudinal ligament between both upper and

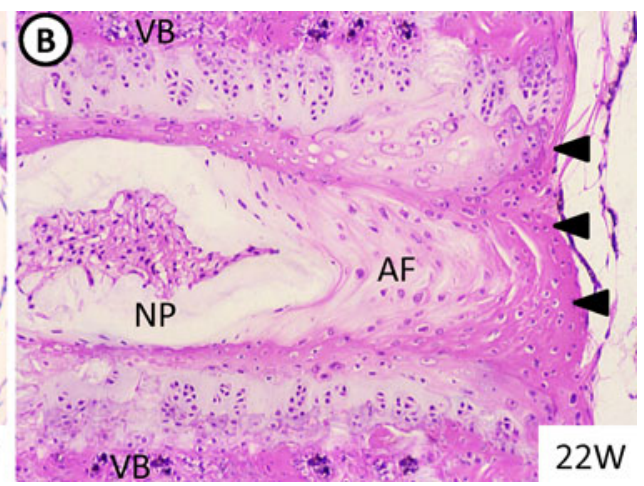

lower vertebral columns in twy/twy mouse. $V B$ vertebral body, $A F$ annulus fibrosus, $N P$ nucleus pulposus, $O S$ osseous bridge, $P L L$ posterior longitudinal ligament (arrow heads); magnification $\times 40$
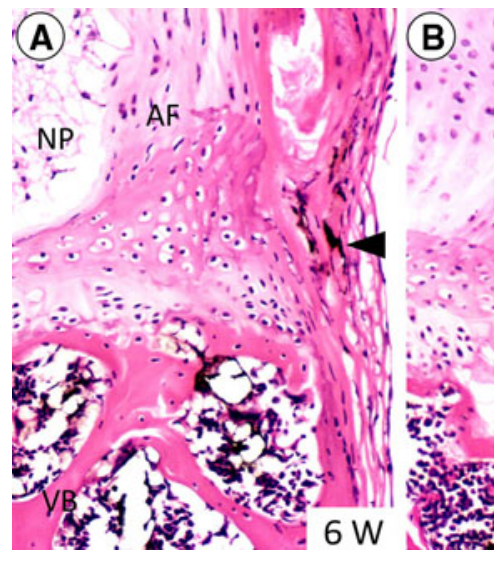

Fig. 2 Photographs showing hematoxylin and eosin (H\&E) staining with casting of vascular meshes. In 6-week-old twy/twy mouse, the ruptured annulus fibrosus with newly produced fine meshes of capillaries (arrowhead) from the enthesis (a). In 18-week-old twy/twy mouse, hyperplastic annulus fibrosus invades the longitudinal ligament, together with abundant capillary meshes (arrow heads) (b). In 22-week-old twy/twy mouse, enlargement of nucleus pulposus

strongly positive in all layers of the cartilaginous tissue of the endplates at all ages, but only weakly positive in the annulus fibrosus cartilaginous tissue. However, the matrix of the herniated nucleus pulposus, and the protruded annulus fibrosus cartilaginous cells with the matrix, were strongly positive for chondroitin 4-sulfate proteoglycan in the twy/twy mice older than 18 weeks (Fig. 3e, f).

\section{Alkaline phosphatase staining}

ALP staining known to be positive for osteoblasts was strongly positive in the hypertrophic cartilaginous cells in the endplate. At 6 weeks of age, osteoblast-like primitive mesenchymal cells appeared in the amorphous cartilaginous tissue within the posterior part of intervertebral disc (Fig. 4a). At 10 weeks of age, ALP-positive osteoblast-like

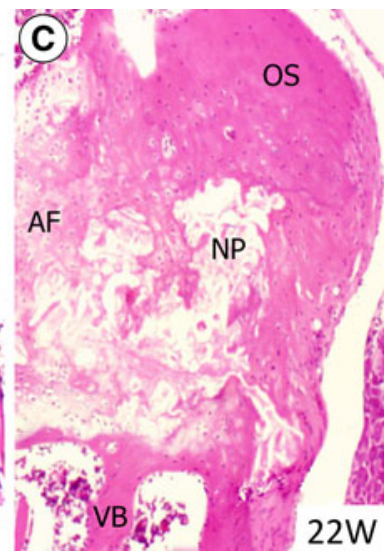

with herniation and rupture of the annulus fibrosus cartilaginous tissue. Many osteoblast-like primitive mesenchymal cells are present. The herniated nucleus pulposus is continuous with the proper nucleus pulposus. Osseous bridges in the longitudinal ligament between both upper and lower vertebral columns (c). $V B$ vertebral body, $A F$ annulus fibrosus, $N P$ nucleus pulposus, $O S$ osseous bridge; magnification $\times 100(\mathbf{a}-\mathbf{c})$

cells were markedly increased within the posterior longitudinal ligament and the intervertebral disc posteriorly (Fig. 4b). At 22 weeks of age, a number of ALP-positive small osteoblast-like mesenchymal cells were decreased with forming osseous bridges in the longitudinal ligament between the upper and lower vertebrae (Fig. 4c).

\section{Discussion}

The present histological study characterized the localization and expression of some factors related to the mechanism of cervical OPLL in the hereditary spinal hyperostotic mouse; twy/twy mice. The main findings of our study were: (1) the volume of the nucleus pulposus increased in all intervertebral discs causing anterior and posterior 


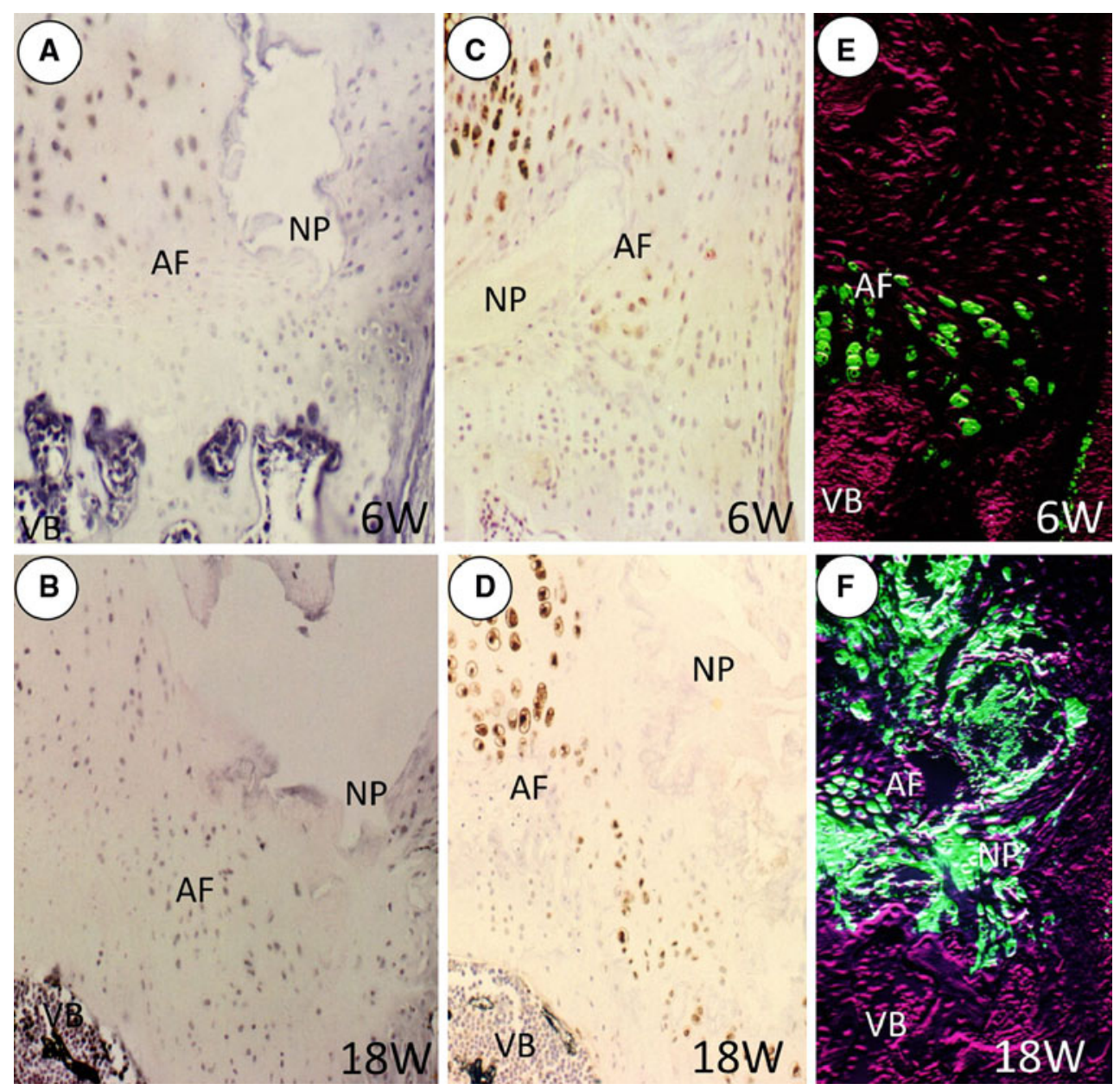

Fig. 3 Photographs showing immunohistochemical staining for proliferating cell nuclear antigen (PCNA) $(\mathbf{a}, \mathbf{b}), \mathrm{S}-100$ protein $(\mathbf{c}, \mathbf{d})$, chondroitin 4-sulfate proteoglycan (e, f). PCNA-positive cells started to appear in 6-week-old $t w y / t w y$ mice around the nucleus pulposus (a). In 18-week-old twy/twy mouse, the number of annulus fibrosus cartilaginous cells surrounding the herniated nucleus increased and those existing at the fronts of protrusions and invasions into the longitudinal ligament were positive for PCNA (b). The ruptured fibrosus cartilaginous cells and those invading the longitudinal ligament are positive for S-100 protein and increased with age (c, d). The matrix of herniated nucleus pulposus and the protruded annulus fibrosus cartilaginous cells with the matrix became strongly positive for chondroitin 4-sulfate proteoglycan with twy/twy mouse aging $(\mathbf{e}, \mathbf{f}) . V B$ vertebral body, $A F$ annulus fibrosus, $N P$ nucleus pulposus; magnification $\times 200(\mathbf{a}-\mathbf{f})$
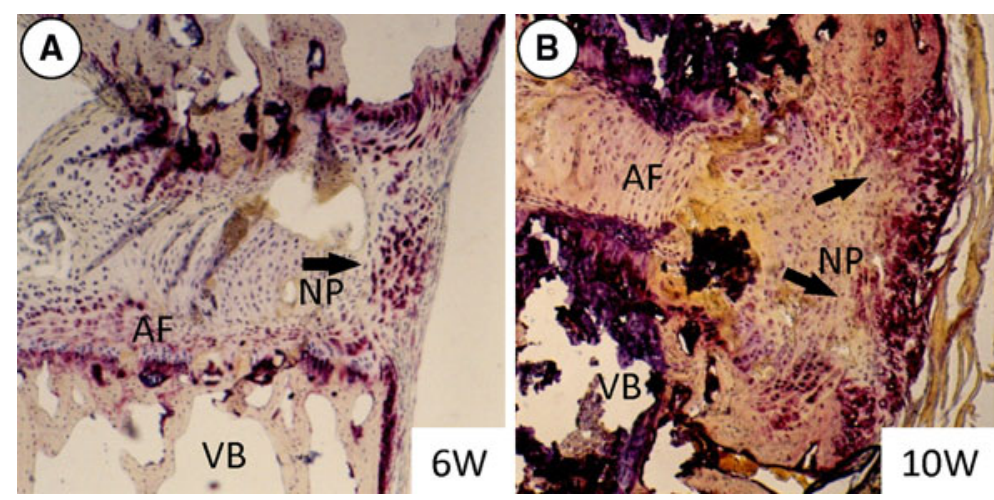

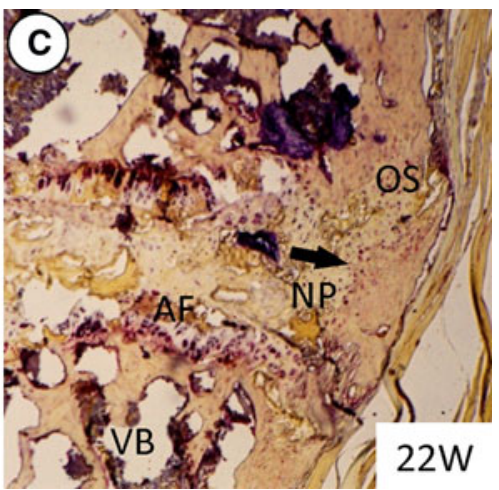

in number with forming osseous bridges. $V B$ vertebral body, $A F$ annulus fibrosus, $N P$ nucleus pulposus, $O S$ osseous bridge; magnification $\times 100(\mathbf{a}-\mathbf{c})$
Fig. 4 Abundant ALP-positive cells (arrows) are found in 6-week old twy/twy mouse (a), and the ALP-positive cells demonstrated an extensive increase in number in 10-week-old twy/twy mouse (b). In 22-week-old twy/twy mouse (c), the ALP-positive cells are decreased 
herniation at 6 weeks of age. The cartilaginous tissue of the annulus fibrosus was disrupted and showed regenerative proliferation with PCNA-positive cartilaginous cells. These cells were S-100 positive and the matrix was positive for chondroitin-4-sulfate proteoglycan, indicating the development of calcification; (2) over the age of 10 weeks, the regenerative cartilaginous tissue of the annulus fibrosus reached the posterior longitudinal ligament together with neovascularization and appearance of PCNA-positive proliferating primitive mesenchymal cells. These cells were considered to be osteoblasts since they were positive for ALP. Together, the serial analysis indicates that OPLL in twyltwy mouse is triggered by the enlargement of the nucleus pulposus followed by herniation, disruption and regenerative proliferation of annulus fibrosus cartilaginous tissues. In addition, the calcification and ossification of the longitudinal ligaments in twy/twy mice as a model of human OPLL seem to be primarily due to genetic abnormalities of mucopolysaccharides metabolism of the vertebral nucleus pulposus.

BMP-2 and TGF- $\beta$ are thought to be involved in the development and/or progression of OPLL lesions. BMP-2 is produced in certain clusters of mesenchymal cells within the posterior longitudinal ligament at levels close to the intervertebral disc and endplate. Abnormal proliferation of chondrocytes (mostly fibrocartilage cells) is thought to contribute to the development of the early stages of ossification [11]. On the other hand, TGF- $\beta 1$ plays important roles in the proliferation of fibroblast-like cells in the histologically torn posterior longitudinal ligament, fibroblasts within the non-calcified layer of the endplate cartilage and chondrocytes of the calcified zone of the endplate, thus enhancing the calcification process and ossification [11]. Within the severely degenerated posterior longitudinal ligament, a high turnover of chondrocytes and fibroblasts occurs, together with a marked proliferation of small blood vessels, particularly in the region close to the enthesis [10]. In human subjects showing hypertrophy of the posterior longitudinal ligament and OPLL, there is an associated proliferation of fibrocartilage and fibroblast-like cells within the ligament prior to ossification [24]. In this regard, the metaplastic proliferative fibrocartilage [13] may also play an important role in early ossification. Moreover, Mine and Kawai [17] have reported that undifferentiated fibroblast- and chondrocyte-like mesenchymal cells within the degenerated ligaments undergo early calcification of the supraspinous ligament, together with the proliferation of irregularly shaped fine collagen fibrils and the increased activity of acid mucopolysaccharide. In the present study, significantly large numbers of fibroblast- and osteoblastlike mesenchymal cells were noted within the posterior longitudinal ligament. These cells were also present in enthesis close to the markedly degenerated intervertebral discs posteriorly. These findings suggest that cellular proliferation contributes to the early development of OPLL.

Degeneration of the cervical intervertebral disc and vertebral endplate is thought to contribute to the progression of OPLL $[15,27]$. In human subjects, histological studies have shown a high prevalence of posterior degeneration of intervertebral disc and a significant cleft formation and fragmentation, in the presence of ossified lesions $[12,27]$. On the other hand, typical features of the cartilaginous endplate include a markedly irregular cleft and fissure formation as well as derangement of the calcified layer of the endplate. Although loss of ALP-positive cells is possible during histological processing of the samples, the presence of a high-ALP activity in this region, which subsequently ossifies, can be a sign of progressive enchondral ossification. The present results indicated that in the twy/twy mouse, development of enchondral ossification within the posterior part of the endplate occurs in close association with the membranous ossification process, which was most significant in the enthesis of the posterior longitudinal ligament. It is possible that these two ossification processes may occur simultaneously in the $t w y /$ twy mouse in close association with changes in matrix proteins constituting the cartilaginous endplate, such as chondroitin 4-sulfate proteoglycan or other proteoglycans [31]. Furthermore, a reconfirmation of the expression of genes related to osteogenesis, angiogenesis, and cell proliferation during an ossification process would be of great interest for future studies.

In conclusion, we showed that enlargement of the nucleus pulposus followed by herniation, disruption and regenerative proliferation of annulus fibrosus cartilaginous tissues participated in the initiation of ossification of posterior longitudinal ligament in twy/twy mouse. In this regard, the cells of the protruded hyperplastic annulus fibrosus invaded the longitudinal ligaments and seemed to induce neovascularization and metaplasia of primitive mesenchymal cells to osteoblasts in the spinal ligaments of twyltwy mice.

Acknowledgments This work was supported in part by grants (2004-2010) to HB and KU from the Investigation Committee on Ossification of the Spinal Ligaments, the Public Health Bureau of the Japanese Ministry of Labor, Health, and Welfare, and by Grant-inAid (B18390411, B19791023, C21591895, C21791389, B22390287, and Young Investigator grant-B22791366) to HB, HN, TY, and KU for General Scientific Research of the Japanese Ministry of Education, Science and Culture.

Conflict of interest No author has any financial ties to any commercial party related to this study.

Open Access This article is distributed under the terms of the Creative Commons Attribution Noncommercial License which permits any noncommercial use, distribution, and reproduction in any medium, provided the original author(s) and source are credited. 


\section{References}

1. Baba H, Furusawa N, Chen Q et al (1997) Potential role of streptozotocin in enhancing ossification of the posterior longitudinal ligament of the cervical spine in the hereditary hyperostotic mouse (twy/twy). Eur J Histochem 41:191-202

2. Baba H, Furusawa N, Chen Q, Imura S, Tomita K (1995) Anterior decompressive surgery for cervical ossified posterior longitudinal ligament causing myeloradiculopathy. Paraplegia 33:18-24

3. Chiba K, Yamamoto I, Hirabayashi H et al (2005) Multicenter study investigating the postoperative progression of ossification of the posterior longitudinal ligament in the cervical spine: a new computer-assisted measurement. J Neurosurg Spine 3:17-23

4. Furukawa K (2006) Current topics on pharmacological research on bone metabolism: molecular basis of ectopic bone formation induced by mechanical stress. J Pharmacol Sci 100:201-204

5. Furusawa N, Baba H, Imura S, Fukuda M (1996) Characteristics and mechanism of the ossification of posterior longitudinal ligament in the tip-toe walking Yoshimura (twy) mouse. Eur J Histochem 40:199-210

6. Furushima K, Shimoonoda K, Maeda S et al (2002) Large-scale screening for candidate genes of ossification of the posterior longitudinal ligament of the spine. J Bone Miner Res 17:128-137

7. Goto S, Yamazaki M (1997) Pathogenesis of ossification of the spinal ligaments. In: Yonenobu K, Sakou T, Ono K (eds) Ossification of the posterior longitudinal ligament. Springer, Tokyo, pp 29-37

8. Horikoshi T, Maeda K, Kawaguchi Y et al (2006) A large-scale genetic association study of ossification of the posterior longitudinal ligament of the spine. Hum Genet 119:611-616

9. Hosoda Y, Yoshimura Y, Higaki S (1981) A new breed of mouse showing multiple osteochondral lesions-twy mouse. Ryumachi 21:157-164

10. Ishida Y, Kawai S (1993) Characterization of cultured cells derived from ossification of the posterior longitudinal ligament of the spine. Bone 14:85-91

11. Kawaguchi H, Kurokawa T, Hoshino Y, Kawahara H, Ogata E, Matsumoto T (1992) Immunohistochemical demonstration of bone morphogenetic protein-2 and transforming growth factorbeta in the ossification of the posterior longitudinal ligament of the cervical spine. Spine 17:33-36

12. Kokubun S, Sakurai M, Tanaka Y (1996) Catilaginous endplate in cervical disc herniation. Spine 21:190-195

13. Lipson SJ (1998) Metaplastic proliferative fibrocartilage as an alternative concept to herniated intervertebral disc. Spine 13:1055-1060

14. Maeda S, Ishidou S, Koga $\mathrm{H}$ et al (2001) Functional impact of human collagen $\alpha 2$ (XI) gene polymorphism in pathogenesis of ossification of the posterior longitudinal ligament of the spine. J Bone Miner Res 16:948-957

15. Matsunaga S, Sakou T (2006) OPLL: disease entity, incidence, literature search, and prognosis. In: Yonenobu K, Nakamura K, Toyama Y (eds) OPLL, 2nd edn. Springer, Tokyo, pp 11-17

16. Matsunaga S, Sakou T, Taketomi E, Nakanishi K (1996) Effects of strain distribution in the intervertebral discs on the progression of ossification of the posterior longitudinal ligaments. Spine 21:184-189
17. Mine T, Kawai S (1995) Ultrastructural observations on the ossification of the supraspinous ligament. Spine 20:297-302

18. Okamoto K, Kobashi G, Washio M et al (2004) Dietary habits and risk of ossification of the posterior longitudinal ligaments of the spine (OPLL): findings from a case-control study in Japan. J Bone Miner Metab 22:612-617

19. Okawa A, Nakamura I, Goto S, Moriya H, Nakamura Y, Ikegawa S (1998) Mutation in Npps in a mouse model of the posterior longitudinal ligament of the spine. Nat Genet 19:271-273

20. Ramos-Remus C, Russell AS, Gomez-Vargas A et al (1998) Ossification of the posterior longitudinal ligament in three geographically and genetically different populations of ankylosing spondylitis and other spondyloarthropathies. Ann Rheum Dis 57:429-433

21. Resnick D, Guerra J Jr, Robinson CA, Vint VC (1978) Association of diffuse idiopathic skeletal hyperostosis (DISH) and calcification and ossification of the posterior longitudinal ligament. Am J Roentgenol 131:1049-1053

22. Resnick D, Shaul SR, Robins JM (1975) Diffuse idiopathic skeletal hyperostosis (DISH): Forestier's disease with extraspinal manifestations. Radiology 115:513-524

23. Sakou T, Taketomi E, Matsunaga S, Yamaguchi M, Sonoda S, Yashiki S (1991) Genetic study of ossification of the posterior longitudinal ligament in the cervical spine with human leucocyte antigen haplotype. Spine 16:1249-1252

24. Sato R, Uchida K, Kobayashi S et al (2007) Ossification of the posterior longitudinal ligament of the cervical spine: histopathological findings around the calcification and ossification front. J Neurosurg Spine 7:174-183

25. Seichi A, Hoshino Y, Ohnishi I, Kurokawa T (1992) The role of calcium metabolism abnormalities in the development of ossification of the posterior longitudinal ligament of the cervical spine. Spine 17:30-32

26. Shingyouchi Y, Nagahama A, Niida M (1996) Ligamentous ossification of the cervical spine in the late middle-aged Japanese men. Its relation to body mass index and glucose metabolism. Spine 21:2474-2478

27. Tanaka M, Nakahara S, Inoue H (1993) A pathologic study of discs in the elderly. Separation between the cartilaginous endplate and the vertebral body. Spine 18:1456-1462

28. Tanno M, Furukawa KI, Ueyama K, Harata S, Motomura S (2003) Uniaxial cyclic stretch induces osteogenic differentiation and synthesis on bone morphogenetic proteins of spinal ligament cells derived from patients with ossification of the posterior longitudinal ligaments. Bone 33:475-484

29. Uchida K, Nakajima H, Yayama T et al (2009) High-resolution magnetic resonance imaging and 18FDG-PET findings of the cervical spinal cord before and after decompressive surgery in patients with compressive myelopathy. Spine 34:1185-1191

30. Watanabe K, Fishman WH (1964) Application of the stereospecific inhibitor L-phenylalanine to the enzymorphology of intestinal alkaline phosphatase. J Histochem Cytochem 12:252-260

31. Yamazaki M, Goto S, Kobayashi S, Terakado A, Moriya H (1994) Bone cells from spinal hyperostosis mouse (twy/twy) maintain elevated levels of collagen production in vitro. $\mathbf{J}$ Bone Miner Metab 12:57-63 